\title{
STUDY OF SERUM FIBROBLAST GROWTH FACTOR 23 IN RELATION TO DIASTOLIC DYSFUNCTION IN CHRONIC KIDNEY DISEASE PATIENTS
}

Sherif Aziz Zaki, Mona Wajdy Ayad*, Heba Selim Elshair, Mohamed Khaled Elfiky**, Dina Adel Ahmed Hassan

Department of Internal Medicine, Clinical and Chemical pathology*, Cardiology and Angiology**, Faculty of Medicine, Alexandria University

\section{INTRODUCTION}

Cardiovascular disease is the most common cause of death in patients with chronic kidney disease. Diastolic dysfunction is an important risk factor resulting in development of advanced cardiovascular diseases. Fibroblast Growth Factor 23 is a . exter (to 23 's effect on the heart is the activation of FGF receptor-4 on cardiac myocytes to stimulate phospholipase C/calcineurin-nuclear factor of activated $\mathrm{T}$ cell signaling. FGF23 is massively elevated in ESRD patients on HD. Elevation of FGF23 is one of the possible causes of diastolic dysfunction.

\section{AIM OF THE WORK}

The aim of this study was to study the relation between FGF 23 and diastolic dysfunction in CKD patients and those maintained on hemodialysis.

\section{PATIENTS AND METHODS}

Patients:

This study included 120 subjects divided into three groups:

Group I: 40 CKD patients on MHD. Group II: 40 CKD patients (stage IV).

Group III: 40 healthy persons as controls. Patients had been selected from those

attending the outpatient Nephrology and Internal Medicine clinics of the Main

Alexandria University Hospital and the Dialysis Unit of Alexandria Fever Hospital.

Their ages ranged between (20-40 years old). Patients maintained on regular hemodialysis at least 6 months.

Methods:

All subjects in this study were subjected to the following regimen:

Full history taking, Full clinical examination, Investigation include (CBC, TIBC, serum urea, serum creatinine, serum uric acid, fasting blood glucose, lipid profile, serum albumin, serum calcium, serum phosphorus, serum Alkaline phosphatase, intact Parathyroid hormone and serum Fibroblast Growth Factor 23 levels, ECG was done for evidence of ischemic heart disease, Echocardiography for evaluation of left ventricular function and wall motion and Statistical analysis of data.

\section{RESULTS}

Significant positive correlations were found between serum FGF-23 levels and serum creatinine, serum intact parathyroid hormone levels (iPTH) and serum phosphorous in CKD patients (stage IV and V). Also between FGF-23 and Left ventricular mass index (LVMI) in CKD patients (stage IV and V).

Table : Correlation between Serum FBG23 with LVM index

\begin{tabular}{|l|c|c|c|c|c|c|}
\hline \multirow{2}{*}{ Serum FBG23 vs. } & \multicolumn{2}{|c|}{$\begin{array}{c}\text { Total cases } \\
(\mathbf{n}=\mathbf{8 0})\end{array}$} & \multicolumn{2}{c|}{$\begin{array}{c}\text { Group I } \\
(\mathbf{n}=\mathbf{4 0})\end{array}$} & \multicolumn{2}{c|}{$\begin{array}{c}\text { Group II } \\
(\mathbf{n}=\mathbf{4 0})\end{array}$} \\
\cline { 2 - 7 } & $\mathbf{r}_{\mathrm{s}}$ & $\mathbf{p}$ & $\mathbf{r}_{\mathrm{s}}$ & $\mathbf{P}$ & $\mathbf{r}_{\mathrm{s}}$ & $\mathbf{p}$ \\
\hline LVM index & 0.558 & $<0.001^{*}$ & 0.432 & $0.005^{*}$ & 0.622 & $<0.001^{*}$ \\
\hline
\end{tabular}

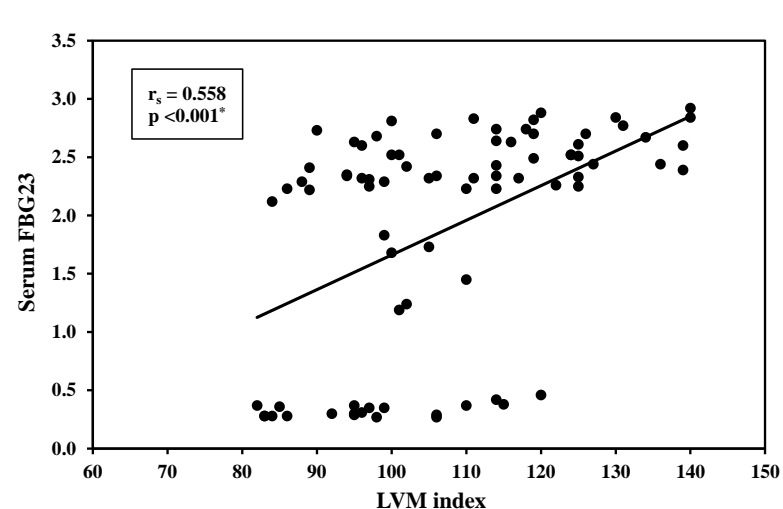

Figure 1: Correlation between serum FBG32 with LVM index in total sample.

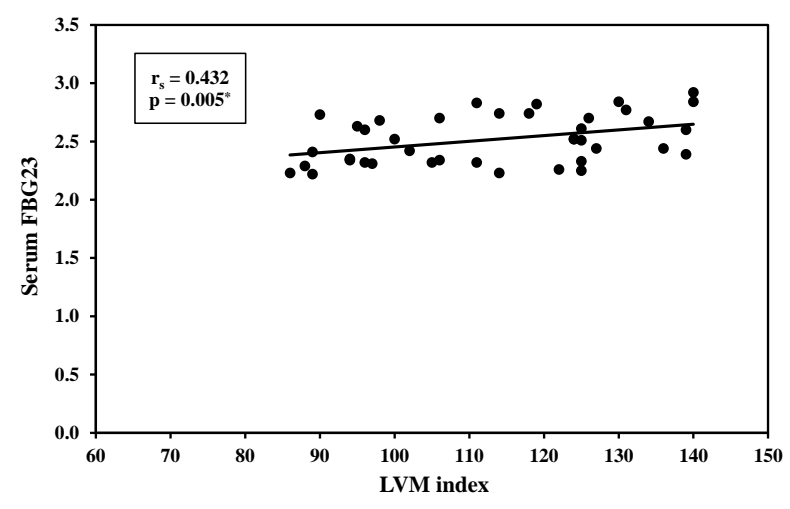

Figure 2: Correlation between serum FBG32 with LVM index in CKD patients on MHD.

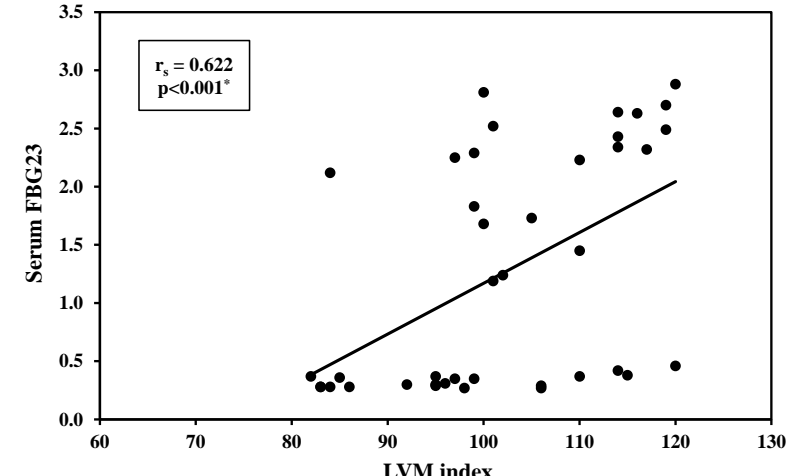

gure 3: Correlation between serum FBG32 with LVM index in CKD patients (stage IV)

\section{CONCLUSION}

Circulating FGF-23 levels are significantly associated with the presence of diastolic dysfunction in CKD patients stage 4 and 5 . Circulating FGF-23 levels are correlated with various other laboratory markers that are established for CKD patients. Serum FGF-23 levels could possibly be used as a valuable marker for the risk of cardiac complications. 